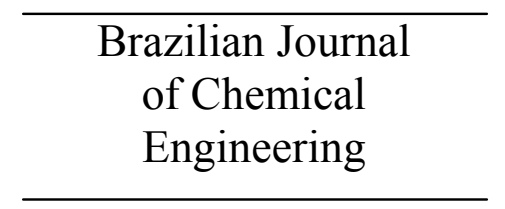

ISSN 0104-6632

Printed in Brazil

www.abeq.org.br/bjche

Vol. 28, No. 01, pp. 45 - 49, January - March, 2011

\title{
C-PHYCOCYANIN EXTRACTION FROM Spirulina platensis WET BIOMASS
}

\author{
C. C. Moraes ${ }^{1}$, Luisa Sala ${ }^{2}$, G. P. Cerveira ${ }^{2}$ and S. J. Kalil ${ }^{2 *}$ \\ ${ }^{1}$ Universidade Federal do Pampa, Engenharia de Alimentos, C. P. 07, 96412-420, Bagé - RS, Brasil. \\ E-mail: engcarolinemoraes@yahoo.com.br \\ ${ }^{2}$ Universidade Federal do Rio Grande, Escola de Química e Alimentos, Phone: + (55) (53) 3233-8754, \\ Fax: + (55) (53) 3233-8645, C. P. 474, 96201-900, Rio Grande - RS, Brasil. \\ E-mail: susana.kalil@vetorial.net
}

(Submitted: February 16, 2010 ; Revised: September 27, 2010 ; Accepted: September 27, 2010)

\begin{abstract}
C-Phycocyanin is a natural blue dye used in food and pharmaceutical industry. In the present study, a simple and efficient method to extract C-phycocyanin from Spirulina platensis wet biomass is reported. The extractions were carried out using six different methods, including chemical (organic and inorganic acid treatment), physical (freezing and thawing, sonication, homogenization) and enzymatic (lysozyme treatment) methods. The extraction using ultrasonic bath in the presence of glass pearls in the biomass proved to be the most efficient method, $56 \%$ higher than using freezing and thawing (the method most frequently used), and presented a extraction yield of $43.75 \mathrm{mg} \cdot \mathrm{g}^{-1}$ and a C-phycocyanin concentration of $0.21 \mathrm{mg} \cdot \mathrm{mL}^{-1}$.

Keywords: Spirulina; Wet biomass; Extraction; C-Phycocyanin.
\end{abstract}

\section{INTRODUCTION}

Phycobiliproteins are accessory photosynthetic pigments that participate in an extremely efficient energy transfer chain in photosynthesis (Róman et al., 2002), responsible for about 50\% of light capitation from cyanobacteria and red algae (Williams et al., 1980). These proteins are assembled into complex structures called phycobilisomes that are attached to the outer surface of the thylakoid membranes (Yu and Glazer, 1982), because chlorophyll absorbs light energy only in a region of the solar spectrum. The excitation energy is posteriorly transferred to the reaction centers placed in the photosynthetic membranes, causing the photosynthetic process. The three main groups of phycobiliprotein are phycocyanins, allophycocyanins and phycoerythrins (Bennett and Bogorad, 1973).

C-phycocyanin (C-PC) could be extracted from cyanobacteria such as Spirulina platensis, which has been widely used in commercial applications in the food and cosmetic industry as a natural blue dye.
Recent studies have demonstrated the hepatoprotective (Romay et al., 2003), anti-inflammatory (Romay et al., 2003; Reddy et al., 2003; Bhat and Madyastha, 2001) and antioxidant (Estrada et al., 2001; Bhat and Madyastha, 2000) properties of C-PC.

Each microorganism has particular characteristics refering to the location of intracellularly produced proteins, meaning that the molecule of interest might be located in the cytoplasm, periplasm or even be stored in some cellular organelle, such as in the mitochondria. Hence, the extraction protocol could vary according to the desired protein.

In general, the extraction method is the key for maximum recovery of phycobiliproteins in the natural state from algae (Niu et al., 2006). The extraction of phycobiliproteins involves cell rupture and release of these proteins from within the cell. The cell walls of cryptophytes are easily disrupted, but those of cyanobacteria are extremely resistant (Siegelman and Kycia, 1978). Thus, the use of variations in the osmotic pressure, abrasive conditions, chemical treatment, freezing-thawing and 
sonication, amongst other disruption methods, are necessary. Mechanical cell disintegration methods are currently preferred for large-scale operations (Gacesa and Hubble, 1990; Kula and Schütte, 1987) since a complete disintegration of the biomass is desired, with high product and activity yields.

Some papers report C-PC extraction from cyanobacterium. Moraes et al. (2010) and Silveira et al. (2007) studied the optimization of extraction from dried biomass. The reported methods to extract C-PC from wet biomass include freezing and thawing (Sony et al., 2008; Sarada et al., 1999; Abalde et al., 1998; Bermejo et al., 2006), sonication (Bermejo et al., 2006; Abalde et al., 1998), homogenization (Sarada et al., 1999), lysozyme treatment (Bermejo et al., 2006; Stewart and Farmer, 1984) and acid treatment (Sarada et al., 1999; Bermejo et al., 2006).

Considering the uses of C-phycocyanin, the aim of this study was to evaluate some methods previously reported to extract C-phycocyanin and other bioproducts, in order to find the best procedure to extract C-phycocyanin from wet biomass of Spirulina platensis considering the extraction yield.

\section{MATERIAL AND METHODS}

\section{Culture Conditions}

Spirulina platensis LEB-52 strain was obtained from the Oceanographic Institute, University of Sao Paulo and kept in the Laboratory of Biochemical Engineering of the Federal University of the Rio Grande as LEB-52. The cyanobacterium was grown and maintained in an open outdoor photo-bioreactor, under uncontrolled conditions, in the south of Brazil. During these cultivations, the water was supplemented with $20 \%$ Zarrouk synthetic medium (Costa et al., 2000). This medium was also used to prepare the biomass for the initial inoculation of each batch. All the reagents used were of analytical grade, obtained from Merck (Darmstadt, Germany) and Synth (São Paulo, Brazil).

\section{Extraction Procedures}

Phycocyanin was extracted from the wet biomass of Spirulina by using the following methods, totalizing 6 methods and 11 assays.

1. Homogenization of cells in a mortar and pestle: Frozen biomass was homogenized in a mortar and pestle in the presence of diatomaceous earth, in the proportion of 5:1 (g biomass: g diatomaceous earth).

2. Freezing and thawing: Biomass was subjected to freezing and thawing for 24 or 48 hours. In the second case (48 hrs), the freezing and thawing procedure was repeated twice, with 24 hrs intervals.

3. Inorganic acid extraction: The wet biomass was treated with different concentrations of hydrochloric acid (2, 4, 6, 8 and $12 \mathrm{M})$ in the proportion 5:1 (g biomass: $\mathrm{mL}$ inorganic acid) and then left for 24 hours at room temperature.

4. Organic acid extraction: The procedure was carried out in the same way used in inorganic acid extraction; in this case the wet biomass was treated with $1 \mathrm{M}$ of acetic acid at room temperature.

5. Lysozyme treatment: Lysozyme was added to the biomass in $0.1 \mathrm{mM}$ sodium phosphate buffer $(\mathrm{pH} 7.0)$ containing $100 \mathrm{mM}$ sodium EDTA solution, to give a final concentration of $100 \mu \mathrm{g} \cdot \mathrm{mL}^{-1}$. The biomass was then incubated for 24 hours at room temperature, according to Boussiba and Richmond (1980).

6. Ultrasonic treatment: Biomass was added to an ultrasonic bath $(50 \mathrm{kHz})$, with glass pearls in the proportion of 1:1.1 (g biomass: g glass pearls) during 40 minutes. (Medeiros et al., 2008).

After extraction, the samples were centrifuged and the supernatant used to verify the extraction yield.

\section{Analytical Procedures}

C-phycocyanin concentration: The C-phycocyanin concentration (CPC) in mg. $\mathrm{mL}^{-1}$ was calculated from the optical densities at 652 and $620 \mathrm{~nm}$, using Equation 1 (Bennett and Bogorad, 1973):

$$
\mathrm{CPC}=\frac{\left(\mathrm{OD}_{620}-0.474 \mathrm{OD}_{652}\right)}{5.34}
$$

Extraction yield: the extraction yield was calculated using Equation 2 (Silveira et al., 2007).

Yield $=\frac{(\mathrm{CPC}) \mathrm{V}}{\mathrm{DB}}$

where Yield is the extraction yield of phycocyanin in $\mathrm{mg}$ of C-phycocyanin/dry biomass ( $\mathrm{g}$ ), $V$ is the solvent volume $(\mathrm{mL})$ and $D B$ is the dry biomass $(\mathrm{g})$.

\section{Statistical Analysis}

To validate the results reproducibility, each essay was done in triplicate. The results were treated by one-way analysis of variance (ANOVA) followed by Tukey's post-hoc test, using Statistica 6.0 (Statsoft Inc., 1998). All analyses were performed considering a level of $95 \%$ of confidence $(\mathrm{p}<0.05)$. 


\section{RESULTS AND DISCUSSION}

The different methods used to extract C-phycocyanin from wet biomass showed the presence of this molecule in the supernatant. Comparison was done among different procedures for C-phycocyanin extraction with freshly harvested biomass and the data are presented in terms of $\mathrm{mg}$ phycocyanin per g dry weight of Spirulina platensis, named the extraction yield.

One of the most important requirements to obtain phycobiliproteins from cyanobacterium is optimizing the extraction and purification steps. Techniques used to extract and purify proteins are also applied to the phycobiliproteins, but a purification procedure that suits a phycobiliprotein from one organism may not be the best method of choice for a corresponding phycobiliprotein from another organism. The release of C-phycocyanin is directly related to cell rupture, but small algae such as Spirulina have resistant multilayered cell walls, making the extraction procedure difficult (Stewart and Farmer, 1984).

In this study, the yields vary between $0.57 \mathrm{mg} \cdot \mathrm{g}^{-1}$ (sonication) and $43.75 \mathrm{mg} \cdot \mathrm{g}^{-1}$ (sonication with glass pearls). The biomass treated with sonication (without glass pearls), lysozyme, $2 \mathrm{M} \mathrm{HCl}, 4 \mathrm{M} \mathrm{HCl}$ and $1 \mathrm{M}$ acetic acid showed low extraction yield, under $2 \mathrm{mg} . \mathrm{g}^{-1}$ and the supernatants were colorless due the low PC content. For this reason, this data were not considered and the following data evaluation considers only the homogenization in mortar and pestle (1), freezing and thawing for $24 \mathrm{~h} \mathrm{(2),} \mathrm{freezing}$

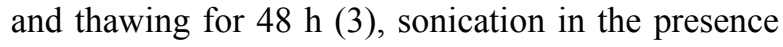
of glass pearls (4), $6 \mathrm{M} \mathrm{HCl}$ (5), $8 \mathrm{M} \mathrm{HCl} \mathrm{(6)} \mathrm{and} 12$ $\mathrm{M} \mathrm{HCl} \mathrm{(7).} \mathrm{The} \mathrm{mean} \mathrm{of} \mathrm{these} \mathrm{results,} \mathrm{standard}$ deviation and significant differences among the assays are presented in Figure 1, where the standard deviation is represented by the error bars and equal letters mean results do not differ statistically at a significance level of 5\% (Tukey's Test).

The treatment using sonication with glass pearls and $12 \mathrm{M} \mathrm{HCl}$ were the ones that reached the highest values for yield, and are statistically equal. Sarada et al. (1999) report the microscopic disintegration of $S$. platensis cell when treated with $\mathrm{HCl}$ concentrations higher than $8 \mathrm{M}$, as we observed in this study. The disintegration promotes the release of C-phycocyanin from inside the cell into the solution. However, because of the low $\mathrm{pH}$, C-phycocyanin precipitated as soon as extracted from the cells. This was not observed when the cells were treated by sonication with glass pearls.

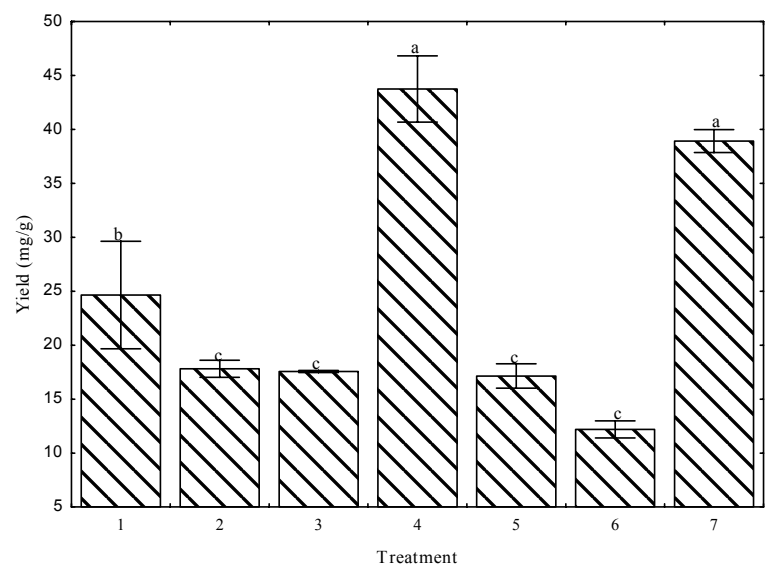

Figure 1: Extraction yield of C-phycocyanin from $S$. platensis cells using different treatments. 1- homogenization in mortar and pestle; 2- freezing and thawing for $24 \mathrm{~h} ; 3$ - freezing and thawing for $48 \mathrm{~h}$; 4- sonication in the presence of glass pearls; 5- $6 \mathrm{M} \mathrm{HCl} ; 6-8 \mathrm{M} \mathrm{HCl}$; 7- $12 \mathrm{M} \mathrm{HCl}$. The standard deviation is represented by the error bars and equal letters means results do not differ statistically at the significance level of 5\% (Tukey's Test).

In recent years, some papers reporting the C-phycocyanin extraction from wet biomass were published (Soni et al., 2008; Bermejo et al., 2006; Sarada et al., 1999; Abalde et al., 1998). In all of them, freezing and thawing was considered to be the best, since it showed higher C-phycocyanin content than the others methods studied by the authors. This method presents some advantages such as being simple, quick (10-12 h), reproducible, robust - since is independent of biomass quantity, free of corrosible material and without presenting significant losses of the biological capacity of the protein. Acker and McGann (2003) suggest that, when the cell is frozen, there is an inevitable intracellular ice formation, resulting in damage to the cell, promoting a better extraction of intracellular substances.

In this paper, we used a method that results in an extraction efficiency $57 \%$ higher than freezing and thawing, presenting only one inconvenience, the difficulty in scale up. Medeiros et al. (2008) suggest that the cavitation phenomenon associated with the abrasion effect generated by the glass pearls during the sonication favored the intracellular protein extraction.

A comprehensive technique must include quick and efficient disruption for a quantitative extraction and recovery of the released pigment. In the present study, a simple and efficient method to extract $\mathrm{C}$-phycocyanin from wet biomass was obtained, and 
presented an extraction yield of $43.75 \mathrm{mg} \cdot \mathrm{g}^{-1}$ and a C-phycocyanin concentration of $0.21 \mathrm{mg} \cdot \mathrm{mL}^{-1}$.

\section{ACKNOWLEDGMENTS}

This work was supported by the Coordenação de Aperfeiçoamento de Pessoal de Nível Superior CAPES and the Conselho Nacional de Desenvolvimento Científico e Tecnológico-CNPq.

\section{NOMENCLATURE}

$\begin{array}{llr}\text { CPC } & \begin{array}{l}\text { C-phycocyanin } \\ \text { concentration }\end{array} & \mathrm{mg} \cdot \mathrm{mL}^{-1} \\ \mathrm{DB} & \text { dry biomass } & \mathrm{g} \\ \mathrm{OD}_{620} & \begin{array}{l}\text { optical densities at } 620 \mathrm{~nm} \\ \mathrm{OD}_{652}\end{array} & \text { optical densities at } 652 \mathrm{~nm} \\ \mathrm{~V} & \text { solvent volume } & \mathrm{mL} \\ \text { Yield } & \begin{array}{l}\text { extraction yield of } \\ \text { phycocyanin in mg of C- }\end{array} \\ & \text { phycocyanin/dry biomass } & \mathrm{g}\end{array}$

\section{REFERENCES}

Abalde, J., Betancourt, L., Torres, E., Cid, A. and Barwell, C., Purification and Characterization of Phycocyanin from the Marine Cyanobacterium Synechococcus sp. IO9201. Plant Science, 136, No. 1, 109 (1998).

Acker, J. P. and McGann, L. E., Protective Effect of Intracellular Ice During Freezing. Cryobiology, 46, No. 2, 197 (2003).

Bennett, A. and Bogorad, L., Complimentary Chromatic Adaptation in a Filamentous BlueGreen Alga. The Journal of Cell Biology, 58, No. 2, 419 (1973).

Bermejo, R., Felipe, M. A., Talavera, E. M. and Alvarez-Pez, J. M., Expanded Bed Adsorption Chromatography for Recovery of Phycocyanins from the Microalga Spirulina platensis. Chromatographia, 63, No. 1-2, 59 (2006).

Bhat, V. B. and Madyastha, K. M., C-Phycocyanin: a Potent Peroxyl Radical Scavenger In Vivo and In Vitro. Biochemical and Biophysical Research Communications, 275, No. 1, 20 (2000).

Bhat, V. B. and Madyastha, K. M., Scavenging of Peroxynitrite by Phycocyanin and Phycocyanobilin from Spirulina platensis: Protection against Oxidative Damage to DNA. Biochememical and Biophysical Research Communications, 285, No. 2, 262 (2001).
Boussiba, S. and Richmond, A., C-Phycocyanin as a Storage in the Blue-Green Alga Spirulina platensis. Archives of Microbilogy, 125, No. 1-2, 143 (1980).

Costa, J. A. V., Linde, G. A., Atala, D. I. P., Mibielli, G. M. and Krüger, R. T., Modelling of Growth Conditions for Cyanobacterium Spirulina platensis in Microcosms. World Journal of Microbiology and Biotechnology, 16, No. 1, 15 (2000).

Estrada, J. E. P., Bescós, P. B. and Fresno, A. M. V., Antioxidant Activity of Different Fractions of Spirulina platensis Protean Extract. Il Farmaco, 56, No. 5-7, 497 (2001).

Gacesa, P. and Hubble, J., Tecnología de las Enzimas. Editorial Acribia, Zaragoza (1900).

Kula, M. R. and Schütte, H., Purification of Proteins and the Disruption of Microbial Cell. Biotechnology Progress, 3, No. 1, 31 (1987).

Medeiros, F. O., Alves, F. G., Lisboa, C. R., Martins, D. S., Burkert, C. A. V. and Kalil, S. J., Ondas Ultrassônicas e Pérolas de Vidro: um Novo Método de Extração de B-Galactosidase para Uso em Laboratório. Química Nova, 31, No. 2, 336 (2008).

Moares, C. C., Burkert, J. F. M. and Kalil, S. J., CPhycocyanin Extraction Process for Large-Scale Use. Journal of Food Biochemistry, 34, No. 1, 133 (2010).

Niu, J-F., Wang, G-C. and Tseng, C-K., Method for Large-Scale Isolation and Purification of RPhycoerytrin Red Alga Polysiphonia urceolata Grev. Protein Expression and Purification, 49, No. 1, 23 (2006).

Reddy, M. C., Subhashini, J., Mahipal, S. V. K., Bhat, V. B., Reddy, P. S., Kiranmai, G., Madyastha, K. M. and Reddanna, P., C-Phycocyanin, a Selective Cyclooxygenase-2 Inhibitor, Induces Apoptosis in Lipopolysaccharide-Stimuled RAW 264.7 Macrophages. Biochemical and Biophysical Research Communications, 304, No. 2, 385 (2003).

Román, R. B., Pez, J. M. A., Fernández, F. G. A. and Grima, E. M., Recovery of Pure BPhycoeritrin from the Microalga Porphyrudium cruentum. Journal of Biotechnology, 93, No. 1, 73 (2002).

Romay, C. H., Gonzaléz, R., Ledón, N., Remirez, D. and Rimbau V., C-Phycocyanin: a Biliprotein with Antioxidant, Anti-Inflammatory and Neuroprotective Effects. Current Protein \& Peptide Science, 4, No. 3, 207 (2003).

Sarada, R., Pillai, M. G. and Ravishankar, G. A., Phycocyanin from Spirulina sp.: Influence of Processing of Biomass on Phycocyanin Yield, 
Analysis of Efficacy of Extraction Methods and Stability Studies on Phycocyanin. Process Biochemestry, 34, No. 8, 795 (1999).

Siegelman, H. W. and Kycia, H. J., Algal biliproteins. In: Hellebust, J.A. and Craigie, J. S., (Eds) Handbook of Phycological Methods. Cambridge University Press, Cambridge (1978).

Silveira, S. T., Burkert, J. F. M., Costa, J. A. V., Burkert, C. A. V. and Kalil, S. J., Optimization of Phycocyanin Extraction from Spirulina platensis Using Factorial Design. Bioresource Technology, 98, No. 8, 1629 (2007).

Soni, B., Trivedi, U. and Madamwar, D., A Novel Method of Single Step Hydrophobic Interaction Chromatography for the Purification of Phycocyanin from Phormidium fragile and its Characterization for Antioxidant Property.
Bioresource Technology, 99, No. 1, 188 (2008).

Statsoft Inc., Statistica for Windows, Version 6.0, 2300 East 14th Street, Tulsa, OK, 74104, USA (1998).

Stewart, D. E. and Farmer, F. H., Extraction, Identification and Quantitation of Phycobiliproteins Pigments from Phototrophic Plankton. Limnology and Oceanography, 29, No. 2, 392 (1984).

Williams, R., Gingrich, J. and Glazer, A., Cyanobacterial Phycobilisomes. Particles from Synechocystis 6701 and Two Pigment Mutants. The Journal of cell Biology, 85, No. 3, 558 (1980).

$\mathrm{Yu}, \mathrm{M} . \mathrm{H}$. and Glazer, N. A., Cyanobacterial Phycobilisomes. Role of the Linker Polypeptides in the Assembly of Phycocyanin. The Journal of Biological Chemistry, 257, No. 7, 3429 (1982). 